University of South Carolina

Scholar Commons

2012

\title{
Application of Electrospinning Technique in the Fabrication of a Composite Electrode for PEMFC
}

Joshua Sightler

Eli McPherson

William A. Rigdon

University of South Carolina - Columbia, rigdonwa@email.sc.edu

Xinyu Huang

University of South Carolina - Columbia, xyhuang@sc.edu

Follow this and additional works at: https://scholarcommons.sc.edu/eche_facpub

Part of the Catalysis and Reaction Engineering Commons, and the Membrane Science Commons

\section{Publication Info}

Postprint version. Published in ECS Meeting Abstracts, 2012, pages 1380-1380.

(C) ECS Meeting Abstracts, 2012, Electrochemical Society

Sightler, J.J., McPherson, E., Rigdon, W.A., Huang, X. (2012). Application of Electrospinning Technique in the Fabrication of a Composite Electrode for PEMFC. ECS Meeting Abstracts, 1380-1380.

This Article is brought to you by the Chemical Engineering, Department of at Scholar Commons. It has been accepted for inclusion in Faculty Publications by an authorized administrator of Scholar Commons. For more information, please contact digres@mailbox.sc.edu. 


\section{Application of Electrospinning Technique in the Fabrication of a Composite Electrode for PEMFC} Joshua Sightler, Eli McPherson, William Rigdon, Xinyu
Huang

University of South Carolina

Mechanical Engineering Dept.

300 Main St., Columbia, SC 29208

Inspired by the original work of Zhang, Brodt and Pintauro [1], the authors investigated the application of electrospinning (E-spin) method for the deposition of catalyst layer of membrane electrode assemblies.

The Pt/C catalysts were mixed with carbon nanotube (CNT), Nafion ${ }^{\mathrm{TM}}$ dispersion and a fiber former, polymer poly-acrylic acid (PAA), to form an ink. The ink was deposited onto aluminum foil attached to a rotating collector via an electrospinning process. The ink composition, mixing procedure, and the E-spin parameters were studied for producing a uniform nanofiber mat on the aluminum substrate. The fiber-mat containing active catalyst ingredients was heat treated and decal transferred onto a Nafion membrane to form a membrane electrode assembly (MEA).

The morphology of the E-Spin MEA was characterized by high resolution scanning electron microscopy (SEM). As shown in Figure 1, the Pt/C forms highly dispersed aggregates attached onto a randomly oriented mat of nanofibers consisting mostly of Nafion and PAA. Fibers are seen ranging from 50 to $200 \mathrm{~nm}$ in diameter. CNTs are believed to be embedded within the nanofiber and preferentially oriented along the fiber.

This morphology is significantly different than that of the traditional MEA.

The performance of the E-spin MEA was characterized and compared with MEAs with the same catalyst type (TKK) and loading $\left(\sim 0.1 \mathrm{mg} / \mathrm{cm}^{2}\right)$ fabricated with ultrasonic deposition techniques to represent a "traditional" electrode. The polarization curve of E-spin MEA and traditional MEA are shown in Figure 2.

Various polarization losses were estimated via I-V curve analysis. Both MEAs have shown reasonable performance at low-level of Pt loading, $0.1 \mathrm{mg}-\mathrm{Pt} / \mathrm{cm}^{2}$. The cyclic voltammogram of the E-Spin MEA as well as the traditional MEA is shown in Figure 3. Compared to the traditional MEA, the E-spin MEA showed higher electrochemical area in the hydrogen UPD range, but lower area in the water activation and Pt oxidation range, interestingly. As a deposition technique, the E-spin process tends to create a large ECSA, as well as highly dispersed $\mathrm{Pt} / \mathrm{C}$ catalyst with excellent electronic and ionic connectivity. CNT within the E-Spin fiber may have contributed to the electronic connectivity of the electrode.

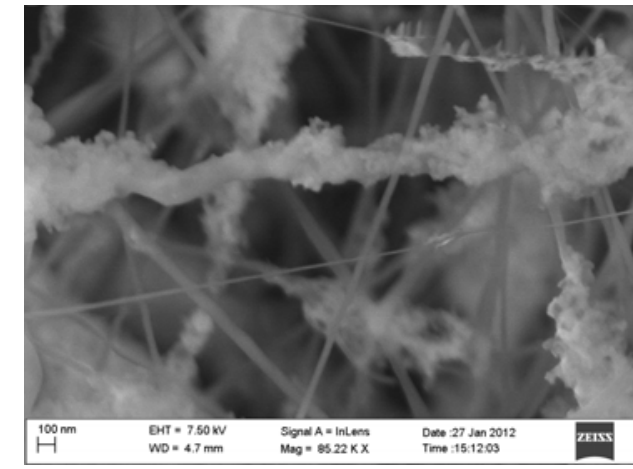

Figure 1. SEM picture of the E-spin electrode.

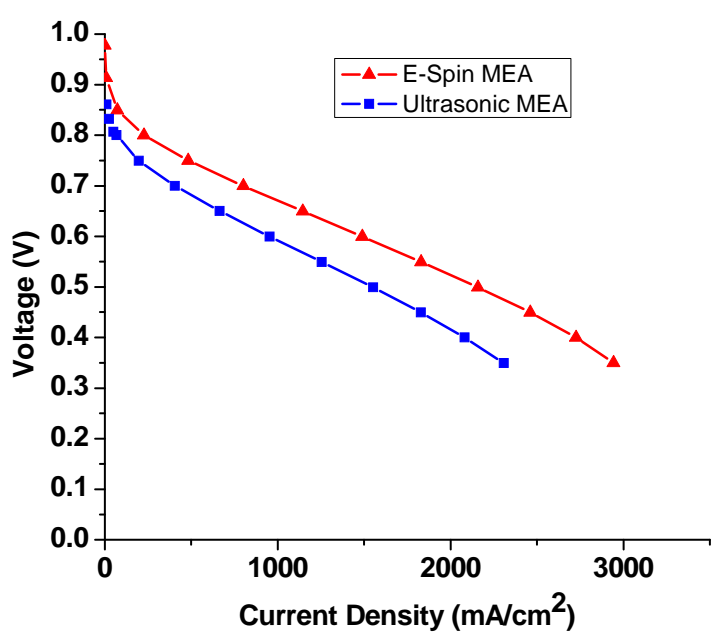

Figure 2. Polarization curve of E-Spin MEA and traditional MEA. Both MEAs were tested at $80^{\circ} \mathrm{C}$ using $\mathrm{H}_{2}$ and $\mathrm{O}_{2}$ at $100 \% \mathrm{RH}$, Stoich $=1.5$ (anode)/ 3.3(cathode), no back pressure.

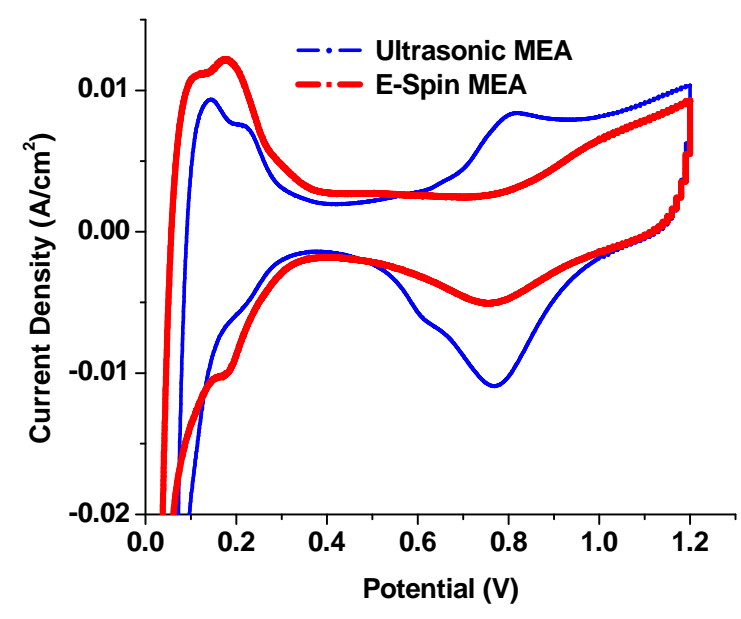

Figure 3. Cyclic voltammagram of E-Spin MEA and traditional MEA obtained at a scan rate of $100 \mathrm{mV} / \mathrm{sec}$. the $\mathrm{Pt}$ loading for both MEA is about $0.1 \mathrm{mg}-\mathrm{Pt} / \mathrm{cm}^{2}$.

\section{References:}

[1] Wenjing Zhang, Matthew W. Brodt, and Peter N. Pintauro, "Nanofiber Cathodes for Low and High Humidity Hydrogen Fuel Cell Operation,” , ECS Trans. 41 (1), 2011, pp891 899. 